\title{
Propriedades físico-químicas de preparados sólidos para refrescos e sucos industrializados
}

\author{
Physicochemical properties from solid preparations for \\ industrialized dry soft-drinks and juices
}

Maria Helena Chaves de Vasconcelos Catão*

Ayonara Dayane Leal da Silva**

Ricardo Miguel de Oliveira**

\section{Resumo}

Objetivo: analisar o pH, a acidez titulável, o teor de sólidos solúveis totais $\left({ }^{\circ}\right.$ Brix) e a quantidade de açúcar contida em 6 refrescos elaborados a partir de preparados sólidos e 4 sucos industrializados disponíveis no mercado brasileiro. Métodos: mensurou-se o pH (analisado em duas temperaturas diferentes) por meio da potenciometria, a acidez titulável pelo método de titulação e a quantidade de açúcar pelo método químico das soluções de Fehling. Para a avaliação do TSST, utilizou-se o refratômetro de Abbé. As bebidas foram avaliadas com três medições para cada amostra. Resultados: todas as bebidas apresentaram $\mathrm{pH}$ endógeno inferior ao considerado crítico para dissolução do esmalte dentário, tendo sido menor nos refrescos do que nos sucos industrializados e sendo inversamente proporcional à temperatura. A quantidade de açúcar foi mais elevada nos preparados sólidos para refresco do que nos sucos industrializados, e os valores estiveram condizentes com os descritos na embalagem. Conclusão: todas as bebidas analisadas apresentaram $\mathrm{pH}$ abaixo do considerado crítico, demonstrando potencial erosivo aos tecidos dentários.

Palavras-chave: $\mathrm{pH}$. Propriedades físicas e químicas. Erosão dentária.

\section{Introdução}

A expectativa de vida da população brasileira está aumentando, e, com a melhora na qualidade de vida, a dentição fica exposta a diversos fatores que contribuem para o desgaste dentário ${ }^{1}$. Há um aumento da prevalência de cáries radiculares e lesões cervicais não cariosas.

As lesões não cariosas têm causa etiológica não bacteriana e são classificadas em: abrasão, erosão e abfração $0^{2,3}$. Abrasão é o desgaste produzido por atividade funcional anormal e está associada ao mecanismo de estresse mecânico, como a escovação traumática. A abfração é a flexão do dente que ocorre, principalmente, no limite amelocementário, ocasionada por sobrecarga oclusal. Há formação de trincas na estrutura dentária, resultando no enfraquecimento por fadiga dessas estruturas, devido à tensão local existente, provocando, também, superfícies desestruturadas e perda gradual de esmalte, dentina e cemento ${ }^{4}$.

A erosão dental é definida como uma perda progressiva dos tecidos dentais relacionado a um processo químico que não envolve ação bacteriana ${ }^{5}$. Esse tipo de perda de tecido dental pode ser causado por fatores extrínsecos e intrínsecos. As causas intrínsecas têm sido relacionadas à anorexia nervosa e bulimia, bem como a qualquer desordem gastroesofágica. As causas extrínsecas envolvem remé-

Doutora em Odontologia. Professora da disciplina de Dentística, Departamento de Odontologia da Universidade Estadual da Paraíba, Campina Grande, PB, Brasil.

*** Acadêmica do curso de Odontologia da Universidade Estadual da Paraíba, Campina Grande, PB, Brasil.

Mestre em Química pela Universidade Federal do Rio Grande do Norte. Técnico em laboratório de química aplicada, Departamento de Química da Universidade Estadual da Paraíba, Campina Grande, PB, Brasil. 
dios ácidos como a vitamina $\mathrm{C}$, além do consumo de comidas e bebidas ácidas ${ }^{6}$.

As lesões erosivas têm sido observadas em indivíduos de todas as faixas etárias. Isso tem acontecido, entre outros fatores, pelas mudanças nos hábitos alimentares da população mundial, que passou a consumir mais produtos industrializados, entre eles, refrigerantes e sucos de frutas, muitas vezes, já no primeiro ano de vida ${ }^{7}$. A ingestão de líquidos na dieta tem sido cada vez mais recomendada, o que se acentua nos países tropicais ${ }^{8}$.

O consumo diário de bebidas ácidas como refrigerantes, refrescos artificiais em pó e sucos naturais tem se tornado cada vez mais frequente. Tais bebidas, geralmente, podem ser classificadas como ácidas, pois possuem $\mathrm{pH}$ inferior a 5 , além de conter ácido cítrico, ácido fosfórico, ácido maleico, citrato de sódio e outros produtos que, comumente, são utilizados na Odontologia para condicionar o esmalte e a dentina ${ }^{9}$.

Por caracterizar um processo cumulativo, ao longo dos anos, o desgaste patológico por erosão dentária pode acarretar perdas severas de esmalte e dentina que exigem reabilitações extensas e de custo elevado ${ }^{10}$.
Os preparados sólidos para refresco (PSRs) são utilizados no preparo de bebidas, devendo ser dissolvidos em água fria, simulando o sabor do suco de fruta natural ${ }^{11,12}$. São popularmente conhecidos como pó para refresco e já estão perfeitamente integrados ao dia a dia do consumidor brasileiro, dada a sua facilidade de preparo, ao seu rendimento e ao seu preço de mercado, bastante inferior, se comparado às bebidas prontas para o consumo, como os refrigerantes, por exemplo, o que o torna mais acessível economicamente, em especial para as populações de renda mais baixa ${ }^{13}$.

Diante do exposto, verifica-se a relevância de avaliar as propriedades físico-químicas dos preparados artificiais sólidos para refrescos, bem como dos sucos industrializados, com base na hipótese de que essas bebidas podem causar erosão dentária e estar relacionadas aos processos cariosos.

\section{Métodos}

Neste experimento, foram analisadas 10 bebidas, sendo 6 preparados sólidos para refrescos e 4 sucos industrializados de diferentes sabores, como apresentado na Tabela 1.

Tabela 1 - Distribuição dos produtos avaliados segundo o sabor e a indústria processadora

\begin{tabular}{|c|c|c|}
\hline Produto & Sabor & Indústria processadora \\
\hline Refresco em pó FRESH ${ }^{\circledR}$ & Maracujá & Krafts Food ${ }^{\circledR}$ \\
\hline Refresco em pó FRESH ${ }^{\circledR}$ & Manga & Krafts Food ${ }^{\circledast}$ \\
\hline Refresco em pó FRESH ${ }^{\circledR}$ & Morango & Krafts Food ${ }^{\circledast}$ \\
\hline Refresco em pó FRESH ${ }^{\circledR}$ & Limão & Krafts Food ${ }^{\circledR}$ \\
\hline Refresco em pó FRESH ${ }^{\circledR}$ & Laranja & Krafts Food ${ }^{\circledR}$ \\
\hline Refresco em pó FRESH ${ }^{\circledR}$ & Abacaxi & Krafts Food ${ }^{\circledR}$ \\
\hline Suco industrializado Maratá ${ }^{\circledR}$ & Maracujá & Maratá Sucos do Nordeste Ltda ${ }^{\circledR}$ \\
\hline Suco industrializado Maratá ${ }^{\circledR}$ & Manga & Maratá Sucos do Nordeste Ltda ${ }^{\circledR}$ \\
\hline Suco industrializado Maratá ${ }^{\circledR}$ & Limão & Maratá Sucos do Nordeste Ltda ${ }^{\circledR}$ \\
\hline Suco industrializado Maratá ${ }^{\circledR}$ & Laranja & Maratá Sucos do Nordeste Ltda ${ }^{\circledR}$ \\
\hline
\end{tabular}

O estudo foi experimental, in vitro, e todas as medições foram realizadas no Laboratório de Química Aplicada do Departamento de Química da Universidade Estadual da Paraíba. Em cada bebida, analisou-se o $\mathrm{pH}$, a acidez total titulável (ATT), o ${ }^{\circ}$ Brix refratométrico e a quantidade de açúcares totais. Utilizou-se o delineamento experimental casualizado com três repetições para cada amostra.

As medições foram realizadas com três lotes diferentes para cada bebida, e o $\mathrm{pH}$ foi analisado em duas temperaturas diferentes, $27{ }^{\circ} \mathrm{C}$ e $5{ }^{\circ} \mathrm{C}$. Para realização das análises dos PSRs, foi necessário realizar a diluição do pó na água filtrada. Para determinar a quantidade de gramas de PSR para cada $\mathrm{mL}$ de água, seguiu-se as determinações da embalagem, que sugeria $20 \mathrm{~g}$ para 2 litros de água. Com a balança digital, pesou-se $2 \mathrm{~g}$ para diluição em $200 \mathrm{~mL}$.

\section{Mensuração do pH}

A obtenção dos valores do $\mathrm{pH}$ foi realizada com o pH-metro digital (HI 221 Calibration Check Microprocessor $\mathrm{pH}$ Meter $^{\circledR}$ - HANNA Instruments) por meio do método potenciométrico. Calibrou-se o aparelho com as soluções tampões e procedeu-se às medições. Transferiu-se $50 \mathrm{~mL}$ da amostra para um becker, sendo realizada a imersão do eletrodo e obtendo-se a leitura.

\section{Mensuração da acidez total titulável}

A ATT, expressa em gramas de ácido cítrico anidro/100 g de suco, foi determinada, em triplicata, por titulação com hidróxido de sódio $(\mathrm{NaOH}) \mathrm{N} / 10$. Padronizou-se o NaOH com o biftalato de potássio, pipetou-se $10 \mathrm{~mL}$ da amostra e adicionou-se 7 gotas 
de solução alcoólica de fenolftaleína e titulou-se com $\mathrm{NaOH}$ N/10 até o aparecimento de uma leve coloração rósea persistente. Anotou-se o volume gasto e calculou-se a acidez através da fórmula:

Acidez (\% Ac, cítrico $)=\mathrm{N}_{\mathrm{AP} \mathrm{x}} \mathrm{F}$ x meq-g (Ac. cítrico) $\mathrm{x} 100$

Amostra

\section{Determinação dos sólidos solúveis totais (ำix)}

A leitura do ${ }^{\circ}$ Brix foi realizada por refratometria através do refratômetro de Abbé (PZO-RL-1 Warszawa ${ }^{\circledR}$, Poland). A calibração foi realizada à temperatura ambiente com água deionizada (índice de refração $=1,3333$ e $0^{\circ}$ Brix a $20{ }^{\circ} \mathrm{C}$ ) antes das medições da amostra.

\section{Determinação dos açúcares totais}

O teor de açúcares totais presente nas bebidas foi analisado pelo método químico. Preparou-se os reagentes: solução A e B do licor de Fehling. Para a padronização dos reagentes, utilizou-se sacarose PA, água destilada e ácido clorídrico. Pipetou-se 25 $\mathrm{mL}$ de amostra e transferiu-se para um balão volumétrico. Adicionou-se $5 \mathrm{~mL}$ de ácido clorídrico e aqueceu-se em banho-maria. Neutralizou-se com base diluída, adicionou-se $5 \mathrm{~mL}$ de acetato de chumbo saturado, completou-se com água destilada e fil- trou-se. Pipetou-se $5 \mathrm{~mL}$ de cada solução de Fehling e transferiu-se para uma cápsula de porcelana. Acrescentou-se $40 \mathrm{~mL}$ de água destilada e aqueceu-se, mantendo-se em ebulição por 4 min. Transferiu-se o filtrado diluído para uma bureta de $25 \mathrm{~mL}$ e titulou-se sobre o licor de Fehling em presença do azul de metileno, até o descoramento da coloração azul. Anotou-se o volume gasto e calculou-se esse valor de acordo com a equação:

$$
\begin{gathered}
\text { Açúcares totais }(\%)=\text { FEC x diluição x } 100 \\
\qquad \mathrm{~V}_{\text {titulação }}
\end{gathered}
$$

Os resultados foram analisados por meio da estatística descritiva (frequências absolutas e percentuais, médias e desvio-padrão). Os dados foram digitados e analisados no Statistical Packag for Social Sciences ${ }^{\circledR}$ (SPSS) na versão 13.0. A margem de erro dos testes estatísticos foi de $5 \%$. O teste utilizado foi $\mathrm{t}$ de student para os resultados de $\mathrm{pH}$, que foram calculados nas duas temperaturas.

\section{Resultados}

A Tabela 2 apresenta os valores médios do $\mathrm{pH}$ de acordo com a temperatura, sendo $27{ }^{\circ} \mathrm{C}$ para a temperatura da bebida natural e $5{ }^{\circ} \mathrm{C}$ para a bebida gelada.

Tabela 2 - Distribuição do pH médio das bebidas em duas temperaturas

\begin{tabular}{l|c|c|c|c|c}
\hline \multicolumn{1}{c|}{ Bebidas } & $\mathrm{pH}$ médio $\left(27^{\circ} \mathrm{C}\right)$ & Desvio-padrão & $\mathrm{pH}$ médio $\left(5{ }^{\circ} \mathrm{C}\right)$ & Desvio-padrão & Valor de $p$ \\
\hline Refresco em pó (maracujá) & 1,81 & 0,06150 & 2,02 & 0,58411 & 0,01 \\
Refresco em pó (manga) & 2,16 & 0,56076 & 2,45 & 0,54781 & 0,01 \\
Refresco em pó (morango) & 1,96 & 0,69870 & 2,11 & 0,59784 & 0,01 \\
Refresco em pó (limão) & 1,91 & 0,69980 & 2,21 & 0,59947 & 0,01 \\
Refresco em pó (laranja) & 1,94 & 0,60910 & 2,17 & 0,59841 & 0,01 \\
Refresco em pó (abacaxi) & 1,99 & 0,60876 & 2,22 & 0,59958 & 0,01 \\
Suco industrializado (maracujá) & 2,95 & 0,48741 & 3,11 & 0,42575 & 0,01 \\
Suco industrializado (manga) & 3,51 & 0,32470 & 3,79 & 0,29875 & 0,02 \\
Suco industrializado (limão) & 3,14 & 0,33689 & 3,25 & 0,32145 & 0,01 \\
Suco industrializado (laranja) & 3,09 & 0,34574 & 3,17 & 0,34101 & 0,00 \\
\hline
\end{tabular}

$\mathrm{O} \mathrm{pH}$ variou de acordo com a temperatura analisada; ou seja, em todos os casos, o $\mathrm{pH}$ foi mais alto quando se analisou a bebida gelada $\left(5{ }^{\circ} \mathrm{C}\right)$ e mais baixo com a bebida natural $\left(27^{\circ} \mathrm{C}\right)$. Existiram evidências estatísticas de que o valor do $\mathrm{pH}$ foi influenciado pela temperatura.
A Tabela 3 contempla os valores da acidez titulável, do ${ }^{\circ}$ Brix e da quantidade de carboidratos totais. 
Tabela 3 - Bebidas analisadas e os valores da ATT, do ${ }^{o}$ Brix e dos carboidratos totais encontrados

\begin{tabular}{l|c|c|c}
\hline \multicolumn{1}{c|}{ Bebidas } & SST (尔Brix) & SST/ATT & $\begin{array}{c}\text { Carboidratos } \\
\text { totais } \\
\mathrm{g} / 200 \mathrm{~mL}\end{array}$ \\
\hline Refresco em pó (maracujá) & 12,65 & 18,88 & $3 \mathrm{~g}$ \\
Refresco em pó (manga) & 13,24 & 16,21 & $2,8 \mathrm{~g}$ \\
Refresco em pó (morango) & 14,05 & 18,54 & $3,4 \mathrm{~g}$ \\
Refresco em pó (limão) & 12,98 & 16,52 & $3,0 \mathrm{~g}$ \\
Refresco em pó (laranja) & 13,99 & 17,01 & $3,2 \mathrm{~g}$ \\
Refresco em pó (abacaxi) & 13,25 & 17,59 & $3,1 \mathrm{~g}$ \\
Média & 13,36 & 17,45 & $3,08 \mathrm{~g}$ \\
Desvio-padrão & 0,245 & 0,348 & 0,375 \\
Coeficiente de variação (\%) & 11,25 & 14,22 & 15,06 \\
Suco industrializado (maracujá) & 12,39 & 17,74 & $2,9 \mathrm{~g}$ \\
Suco industrializado (manga) & 12,98 & 15,98 & $2,1 \mathrm{~g}$ \\
Suco industrializado (limão) & 12,27 & 17,45 & $2,6 \mathrm{~g}$ \\
Suco industrializado (laranja) & 12,65 & 16,74 & $2,4 \mathrm{~g}$ \\
Média & 12,57 & 16,97 & $2,5 \mathrm{~g}$ \\
Desvio-padrão & 0,378 & 0,413 & 0,405 \\
Coeficiente de variação (\%) & 12,47 & 13,02 & 13,01 \\
\hline
\end{tabular}

\section{Discussão}

Vários estudos relatam que bebidas com $\mathrm{pH}$ abaixo daquele crítico para o esmalte dental podem causar desmineralização na superfície do dente. $\mathrm{O}$ estudo de Corso et al. ${ }^{14}$ (2002) indica que bebidas com $\mathrm{pH}$ inferior a 5,5 já podem causar erosão dentária, principalmente se o consumo for frequente. Segundo Sobral et al. ${ }^{15}$ (2000), abaixo desse valor de $\mathrm{pH}$ crítico para desmineralização, os cristais de apatita começam a dissolver-se, e o esmalte está em risco de sofrer o processo de descalcificação. De acordo com O'Sullivan et al. ${ }^{16}$ (2000), uma bebida com $\mathrm{pH}$ abaixo desse valor será capaz de causar erosão no esmalte dentário, mesmo que grande parte da solução seja deglutida e pouco fique misturada com a saliva.

No presente trabalho, todas as bebidas analisadas apresentaram $\mathrm{pH}$ inferior a 4,0, o que sugere alto poder erosivo. Todos os preparados sólidos para refresco apresentaram-se com $\mathrm{pH}$ mais ácido do que os sucos industrializados. Com relação ao sabor, o refresco de maracujá foi o que apresentou $\mathrm{pH}=$ $(1,81)$ mais baixo e o refresco de manga o $\mathrm{pH}=(2,16)$ mais alto. Nos sucos industrializados, os resultados foram iguais quanto ao sabor. Dados semelhantes foram encontrados por Cavalcanti et al. ${ }^{17}$ (2006), onde o suco de maracujá foi o que apresentou $\mathrm{pH}$ mais baixo.

No que concerne ao $\mathrm{pH}$ e à temperatura das bebidas, verificou-se que o $\mathrm{pH}$ foi inversamente proporcional à temperatura, ou seja, foi menor nas bebidas naturais e com a temperatura mais alta. Esses achados condizem com estudos de Corso et al. ${ }^{14}$ (2002), em que os sucos artificiais de limão apresentaram $\mathrm{pH}$ menos ácido nas bebidas geladas.
A temperatura de uma bebida constitui-se num fator modulador de seu efeito erosivo, influenciando a capacidade erosiva de uma solução devido a reações químicas que são temperatura-dependentes ${ }^{18}$. Os estudos de Amaechi et al. ${ }^{18}$ (1999) e de Barbour et al. ${ }^{19}$ (2006) demonstraram que o contato do esmalte e da dentina com bebidas ácidas em baixas temperaturas reduz a dissolução mineral desses substratos.

A análise da quantidade de sólidos solúveis ( ${ }^{\circ}$ Brix) é um método amplamente aceito pela comunidade acadêmica. Está relacionada à viscosidade da substância. Quanto maior o escoamento do líquido, maior será a adesão à superfície ${ }^{20}$. Pode-se observar que as médias dos SSTs (Brix) dessas bebidas diferiram entre si, apresentando-se média maior para os preparados sólidos para refrescos em relação aos sucos industrializados, o que demonstra maior potencial para gerar lesões de cárie dentária.

Neste estudo, o valor do Brix variou de 12,27 a 14,05 , observando-se um maior valor do Brix nos refrescos, sendo o de morango o valor mais alto (Brix $=14,05)$. Todos os valores encontrados nos sucos industrializados foram menores que nos refrescos, sendo o valor mais baixo no suco industrializado de limão (Brix = 12,27).

Ao observar-se a AAT das diferentes bebidas, o refresco de maracujá mostrou-se o que mais tempo demanda para ser neutralizado $(\mathrm{AAT}=18,88)$ e o de manga (AAT $=16,21$ ), o que neutraliza mais rapidamente. Para os sucos industrializados, a AAT variou de 15,98 a 17,74 , sendo encontrado maior valor também para o sabor maracujá e menor para o sabor manga.

Bebidas erosivas com elevada acidez titulável mantêm o meio bucal ácido por um período maior de tempo e proporcionam acentuada dissolução mineral previamente ao processo de neutralização do $\mathrm{pH}^{21,22}$.

A quantidade total de açúcar encontrada nessas bebidas variou de $2,1 \mathrm{~g}$ a $3,4 \mathrm{~g}$ para $200 \mathrm{~mL}$ de bebida. Os refrescos apresentaram maior concentração total de açúcar em relação aos sucos industrializados analisados, podendo ser considerados, portanto, bebidas com maior poder cariogênico. Os valores foram condizentes com os descritos nas embalagens.

O consumo excessivo de sucos e bebidas adocicadas, particularmente nas refeições, deve ser visto com atenção, uma vez que pode contribuir significativamente para o aumento do potencial erosivo da dieta líquida. O consumo de sucos, refrigerantes, refrescos nas refeições são apontados, assim, como fatores de risco para o desenvolvimento da erosão dentária e de lesões de cárie dentária ${ }^{17,23,24}$.

Preparado sólido para refresco é um produto à base de suco ou extrato vegetal de sua origem e açúcares, podendo ser adicionado de edulcorantes hipocalóricos e não calóricos, destinado à elabora- 
ção de bebida para consumo imediato, pela adição de água potável ${ }^{23}$. Todos os preparados sólidos para refrescos analisados apresentaram apenas $1 \%$ de polpa desidratada da fruta. Os sucos industrializados apresentaram 39\% de concentração de polpa da fruta, dados que estão de acordo com as normas da Anvisa ${ }^{25}$.

Por ser um experimento in vitro, este estudo apresentou a vantagem de fornecer dados isolados de variáveis sem a interferência de outros fatores. Entretanto, não houve reprodução das condições bucais, importantes para a análise propriamente dita do potencial erosivo de bebidas sobre a superfície dental. Isso constituiu uma limitação deste trabalho, impondo a necessidade de experimentos que avaliem esse potencial erosivo na superfície dentária.

\section{Conclusão}

Todas as bebidas analisadas possuem $\mathrm{pH}$ ácido, o qual varia de acordo com a temperatura, sendo mais elevado na bebida com maior temperatura. Os preparados sólidos para refresco mostraram-se com maior poder de causar erosão e cárie dentária do que os sucos industrializados. Os resultados sugerem que, se consumidas com frequência, essas bebidas podem contribuir para o desenvolvimento de erosão e cárie dentária.

\section{Abstract}

Objective: to analyze $\mathrm{pH}$, titratable acidity, total soluble solid content ( ${ }^{\circ}$ Brix), and the quantity of sugar contained in 6 refreshments, made from prepared solids and 4 industrialized juices available in the Brazilian market. Methods: the $\mathrm{pH}$ was measured (analyzed at two different temperatures) by potentiometry, titratable acidity by the titration method, and the quantity of sugar by the chemical method of Fehling's solutions. For the assessment of the TSST, the Abbé refractometer was used. Drinks were assessed with 3 measurements for each sample. Results: all drinks showed endogenous $\mathrm{pH}$ below what was considered critical for the dissolution of dental enamel. It was lower in refreshments than industrialized juices, and inversely proportional to temperature. The quantity of sugar was higher in prepared solids than industrialized juices and the values were consistent with its package description. Conclusion: all beverages analyzed presented $\mathrm{pH}$ below critical, which indicates an erosive potential to dental tissues.

Keywords: pH. Physical and chemical properties. Dental erosion.

\section{Referências}

1. Moraes, MLMA. Lesões dentárias não cariosas: revisão de literatura [Trabalho de Conclusão de Curso]. São Paulo: Faculdade Santa Marcelina; 2012.

2. Kliemann C. Lesões cervicais não-cariosas por abrasão (escovação traumática). J Bras Clin Odontol Int 2002; 6(33): 204-9.

3. Zero DT. Etiology of dental erosion: extrinsic factors. Eur J Oral Sci 1996; 104(Pt 2):162-77.

4. Lee WC, Eakle WS. Possible role of tensile stress in the etiology of cervical erosive lesions of teeth. J Prosthet Dent 1984; 52(3):374-80.

5. Barron RP, Carmichael RP, Marcon MA, Sandor GK. Dental erosion in gastroesophageal reflux disease. J Can Dent Assoc 2003; 69:84-9.

6. Erickson PR, Alevizos DLA. Soft drinks: hard on teeth. Northwest Dent 2001; 80(2):15-9.

7. Nunn JH, Gordon PH, Morris AJ, Pine CM, Walker A. Dental erosion-changing prevalence. Areview of british national children's surveys. Int J Paedriatic Dent 2003; 13(2):98-105.

8. Sobral MAP, Luz MAAC, Gama-Teixeira A, Netto NG. Influence of the liquid acid diet on the development of dental erosion Pesqui Odontol Bras 2000; 14(4):406-10.

9. Prati C, Montebugnoli L, Suppa P, Valdre G, Mongiorgi R. Permeability and Morphology of dentin after erosion induced by acidic drinks. J Periodontol 2003; 74(4):428-36.

10. Lussi A, Jaeggi T. Dental erosion in children. Monogr Oral Sci 2006; 20:140-51.

11. Drouzas AE, Tsami E, Saravacos GD. Microwave/vacuum drying of model fruit gels. J Food Engineering 1999; 39: $117-22$

12. Notter GK, Taylor DH, Walker LH. Stabilized lemonade powder. Food Technology 1955; 9(10):503-5.

13. Instituto Nacional de Metrologia, Qualidade e Tecnologia (Inmetro). Análise com preparado sólido artificial para refresco (pó para refresco) realizada pelo Laboratório Central de Saúde Pública - Noel Nutels, da Secretaria de Estado de Saúde do Rio de Janeiro [online]; 1999 [citado 2012 Mar 10]. Disponível em URL: http://www.inmetro.gov.br/consumidor/ produtos/refresco.asp.

14. Corso AC, Hugo FN, Padilha DM. pH e tiratibilidade de sucos artificiais de limão. Rev Fac Odontol Porto Alegre 2002; 43:30-3.

15. Sobral MAP, Luz MAAC, Teixeira AG, Garone Netto N. Influência da dieta líquida ácida no desenvolvimento de erosão dental. Pesqui Odontol Bras 2000; 14:406-10.

16. O'Sullivan EA, Curzon MEJ. Salivary factors affecting dental erosion in children. Caries Res 2000; 34:82-7.

17. Cavalcanti AL, Oliveira KF, Paiva PS, Dias MVR, Costa SKP, Vieira FF. Determinação dos sólidos solúveis totais ( $\left.{ }^{\circ} \mathrm{Brix}\right)$ e pH em bebidas lácteas e sucos de frutas industrializados. Pesq Bras Odontoped Clin Integr 2006; 6(1):57-64.

18. Amaechi BT, Higham SM, Edgar WM. Factors influencing the development of dental erosion "in vitro" enamel type, temperature and exposure time. J Oral Rehabil 1999; 26(8):624-30 
19. Barbour ME, Finke M, Parker DM, Hughes JA, Allen GC, Addy M. The relationship between enamel softening and erosion caused by soft drinks at a range of temperatures. J Dent 2006; 34(3):207-13.

20. Anusavice, KJ. Phillips materiais dentários. 11. ed. Rio de Janeiro: Elsevier; 2005.

21. Larsen MJ, Nyvad B. Enamel erosion by some soft drinks and orange juices relative to their $\mathrm{pH}$, buffering effect and contents of calcium phosphate. Caries Res 1999; 33(1):81-7.

22. Edwards M, Creanor SL, Foye RH, Gilmour WH. Buffering capacities of soft drinks: the potential influence on dental erosion. J Oral Rehabil 1999; 26(12):923-7.

23. Mateos A. Brasileiros comem cada vez mais e com pior qualidade. Rev Assoc Paul Circ Dent 1999; 53(1):8-14.

24. Cavalcanti CL, Goncalves VB, Valença AMG, Vieira RKA, Cavalcanti AL. Avaliação da dieta líquida ingerida pelos pacientes atendidos na clínica de odontopediatria da UFPB: $\mathrm{pH}$ e valor nutricional. Pesq Bras Odontoped Clin Integr 2002; 2(2/3):69-75.

25. Brasil. Ministério da Saúde. Agência Nacional de Vigilância Sanitária. Decreto no. 2.314, de 4 de setembro de 1997 [online]; 1997. Disponível em URL: http://www.anvisa.gov.br/ legis/decretos/2314_97.htm.

Endereço para correspondência:

Ayonara Dayane Leal da Silva

Rua João Pessoa Neto, 100

Bairro Juracy Palhano

58103-233

Campina Grande-PB

Fones: (83) 9128-0661/8836-4425

E-mail: narasleal@hotmail.com

Recebido: 05/09/2012. Aceito: 26/06/2013. 